\title{
Großes Missverständnis bei Pflichtarbeitszeit
}

\author{
Ärzte, die ihre Praxisnachfolge dadurch organisieren, dass sie ihren \\ Arztsitz an ein MVZ abgeben, müssen seit 2016 dort mindestens \\ drei Jahre als Angestellter weiterarbeiten. Dabei haben sie bei der \\ Reduktion ihrer Arbeitszeit aber mehr Spielraum als gedacht.
}

D as Bundessozialgericht (BSG) hat 2016 (Az.: B 6 KA 21/15 R) entschieden, dass ein Arzt, der auf seine Zulassung verzichtet, um als Angestellter für ein Medizinisches Versorgungszentrum (MVZ) tätig zu werden, die Absicht haben muss, diese Tätigkeit für mindestens drei Jahre auszuüben. Heute stellt sich in der Praxis immer noch häufig die Frage, in welchem Umfang der angestellte Arzt seine Tätigkeit reduzieren kann, ohne die Nachbesetzbarkeit der vakant werdenden Arztstelle beziehungsweise des Arztsitzes zu gefährden. Die Antwort hierauf scheint stets dieselbe zu sein: Der Arzt könne erst nach zwölfmonatiger Tätigkeit seinen Beschäftigungsumfang um eine Viertelstelle und erst nach weiteren zwölf Monaten erneut um eine Viertelstelle reduzieren. Diese Antwort ist aber falsch. Vielmehr sind Arzt und MVZ - oder auch die anstellende Praxis - frei, wann und in welchem Umfang sie die Tätigkeit reduzieren, solange der Arzt nur mindestens mit einem Versorgungsauftrag einer Viertelstelle drei Jahre angestellt ist.

\section{Richter wollten Beispiel nennen}

Die Ursachen für das falsche Verständnis der BSG-Entscheidung sind einfach nachzuvollziehen. Im Terminbericht des BSG zu seiner Sitzung vom 4. Mai 2016 findet sich folgender Satz: „Die zu fordernde Absicht des (ehemaligen) Vertragsarztes, im MVZ tätig zu werden, wird sich - wie der Senat für die Zukunft klarstellt - grundsätzlich auf eine Tätigkeitsdauer im MVZ von drei Jahren be- ziehen müssen, wobei die schrittweise Reduktion des Tätigkeitsumfangs um eine Viertelstelle in Abständen von einem Jahr unschädlich ist." Diese Aussage hat sich in den Köpfen aller Beteiligten dahin gehend verdichtet, dass nur diese Möglichkeit der Zeitreduktion bestehe. Im Urteil selbst, und nur dieses ist maßgeblich, stellt das BSG aber klar, dass es sich bei der Reduktion um eine Viertelstelle und nach jeweils einem Jahr um ein Beispiel handelt. Der relevante Satz im Urteil lautet: „Wenn ein solcher Arzt zunächst ein Jahr in dem Umfang im MVZ tätig war, in dem er zuvor als zugelassener Arzt an der Versorgung teilgenommen hat, seinen Beschäftigungsumfang in den beiden folgenden Jahren aber vermindert, etwa indem er jeweils seinen Beschäftigungsumfang schrittweise um den Anrechnungsfaktor ein Viertel reduziert, wirkt sich dies nicht auf das Nachbesetzungsrecht des MVZ aus, sodass insoweit die allgemeinen Regelungen gelten."

Die entscheidenden Worte sind also „etwa indem“. Das Wort „etwa“ ist nach dem Duden das Synonym für „beispielsweise". Exakt in dieser Weise benutzt der sechste Senat es auch. Im selben Urteil führt er zum Beispiel zu den unvorhersehbaren Umständen, die trotz einer Beendigung der Anstellung vor Ablauf der drei Jahre die Nachbesetzung nicht gefährden, wörtlich aus, dies könne „etwa der Fall sein, wenn der Arzt erkrankt oder aus zwingenden Gründen seine Berufs- oder Lebensplanung ändern musste". In derselben Entscheidung verweist der BSG-Senat mit den Worten „etwa dem Versterben des Arztes" auf eine Veröffentlichung in der juristischen Fachliteratur. Im Original, auf das sich die Richter beziehen, lautet die Formulierung „zum Beispiel wegen Tod oder Berufsunfähigkeit“".

In einem Urteil des Senats vom 3. August 2016 (Az:: B 6 KA 31/15 R) wird das Wort „etwa" sogar sieben Mal als Synonym für „beispielsweise“ benutzt. In einem Urteil aus dem Jahr 1997 (Az.: 6 RKa 52/97) nutzt der sechste Senat schließlich das Wortpaar "etwa indem“ in folgender Weise: „Zu Recht weist insoweit die Revision darauf hin, dass das Gesetz ein derartiges Ziel mit einfachen sprachlichen Mitteln hätte ausdrücken können, etwa indem in den Satz 1 das Wort ,allein' oder das Wort ,ausschließlich ' hätte eingefügt werden können.“

Im Ergebnis ist es auch völlig stringent, dass die genannte Möglichkeit der Reduktion von einer Viertelstelle pro Jahr nur ein Beispiel ist. Das BSG betont nämlich in seiner Entscheidung, dass die Privilegierung des Verzichts mit nachfolgender Anstellung darauf beruht, dass der Arzt seine Tätigkeit im Vertragsarztsystem fortführt und nur den Status vom niedergelassenen Vertragsarzt zum Angestellten wechselt. Es zählt also nur der Status als solches. Dies wird nochmals unmissverständlich hervorgehoben, indem bekräftigt wird, dass sich der ,Tätigkeitswille nur auf die Tätigkeit als solche" beziehen müsse. Die Aussagen des BSG sind eindeutig. Ein Arzt kann jederzeit seine Tätigkeit auf eine halbe oder Dreiviertelstelle reduzieren - solange er den Status des Angestellten behält und sich sein Tätigkeitswille auf die ärztliche Tätigkeit als solche bezieht. Nur diese Auslegung wird schließlich dem allgemeinen Recht auf Arbeitszeitreduktion nach dem Teilzeit- und Befristungsgesetz gerecht. Dr. Ingo Pflugmacher 